\title{
Fibular Vein
}

National Cancer Institute

\section{Source}

National Cancer Institute. Fibular Vein. NCI Thesaurus. Code C154772.

A vein that arises from the plantar veins of the foot, accompanies the peroneal artery, and travels up the back of the leg to join the anterior and posterior tibial veins in forming the popliteal vein on the posterior surface of the knee. 